\title{
Targeting the oxidative stress response system of fungi with redox-potent chemosensitizing agents
}

\author{
Jong H. Kim ${ }^{1}$, Kathleen L. Chan ${ }^{1}$, Natália C. G. Faria ${ }^{2}$, M. de L. Martins ${ }^{2}$ and Bruce C. Campbell ${ }^{1}$ * \\ 1 Plant Mycotoxin Research Unit, Western Regional Research Center, USDA-ARS, Albany, CA, USA \\ ${ }_{2}^{2}$ Instituto de Higiene e Medicina Tropical/Centro de Recursos Microbiológicos, Universidade Nova de Lisboa, Lisboa, Portugal
}

\section{Edited by:}

Karin Thevissen, Catholic University of

Leuven, Belgium

\section{Reviewed by:}

Tom Coenye, University of Ghent, Belgium

Paul Cos, Antwerp University,

Belgium

\section{*Correspondence:}

Bruce C. Campbell, Plant Mycotoxin

Research Unit, Western Regional

Research Center, USDA-ARS, 800

Buchanan Street, Albany, CA 94710,

USA.

e-mail: bruce.campbell@ars.usda.gov
The cellular antioxidant system is a target in the antifungal action of amphotericin $B(A M B)$ and itraconazole (ITZ), in filamentous fungi. The sakA $\Delta$ mutant of Aspergillus fumigatus, a mitogen-activated protein kinase (MAPK) gene deletion mutant in the antioxidant system, was found to be more sensitive to AMB or ITZ than other A. fumigatus strains, a wild type and a mpkC $\triangle$ mutant (a MAPK gene deletion mutant in the polyalcohol sugar utilization system). Complete fungal kill ( $\geq 99.9 \%$ ) by ITZ or AMB was also achieved by much lower dosages for the sakA $\Delta$ mutant than for the other strains. It appears $m s n A$, an Aspergillus ortholog to Saccharomyces cerevisiae MSN2 (encoding a stress-responsive $\mathrm{C}_{2} \mathrm{H}_{2}$-type zinc-finger regulator) and sakA and/or mpkC (upstream MAPKs) are in the same stress response network under tert-butyl hydroperoxide ( $t$ - $\mathrm{BuOOH})$-, hydrogen peroxide $\left(\mathrm{H}_{2} \mathrm{O}_{2}\right)$ - or AMB-triggered toxicity. Of note is that ITZ-sensitive yeast pathogens were also sensitive to $t$-BuOOH, showing a connection between ITZ sensitivity and antioxidant capacity of fungi. Enhanced antifungal activity of AMB or ITZ was achieved when these drugs were co-applied with redox-potent natural compounds, 2,3-dihydroxybenzaldehyde, thymol or salicylaldehyde, as chemosensitizing agents. We concluded that redox-potent compounds, which target the antioxidant system in fungi, possess a chemosensitizing capacity to enhance efficacy of conventional drugs.

Keywords: amphotericin B, itraconazole, natural compounds, chemosensitization, Candida, Cryptococcus, Aspergillus, oxidative stress response

\section{INTRODUCTION}

Recent studies have shown that one of the antimicrobial modes of action of certain drugs involves cellular oxidative stress response in pathogens, which further contributes to the death of microorganisms. Thus, these types of drugs could be defined as oxidative stress drugs.

Examples include amphotericin B (AMB). Although AMB is known as a fungicidal drug by causing ion leakage, studies have shown that forming channels in the cellular membrane was not the sole mechanism of AMB activity (Palacios et al., 2007). Instead, oxidative stress triggered by $\mathrm{AMB}$ could be one of the contributing mechanisms for AMB fungicidality. For instance, addition of antioxidants, such as reduced glutathione (GSH), cysteine, etc., could revive endospores of Coccidioides immitis treated with AMB (Graybill et al., 1997 and references therein), indicating the involvement of cellular oxidative stress in AMB activity. Results showed that superoxide radical-mediated oxidative damage was involved in AMB activity (Okamoto et al., 2004). Other studies further support involvement of cellular oxidative stress as a component of the antifungal mode of action of AMB (SokolAnderson et al., 1986, 1988; Blum et al., 2008; An et al., 2009; González-Párraga et al., 2011).

Itraconazole (ITZ) is another example of an oxidative stress drug. The main mechanism of action of ITZ is similar to other azole agents by inhibiting fungal cytochrome P450 oxidasemediated biosynthesis of ergosterol, ultimately inhibiting fungal growth. However, a recent study with the Ddr48 protein of Candida albicans indicated the oxidative stress response of this pathogen was also triggered by ITZ treatment (Dib et al., 2008). The C. albicans Ddr48 protein is essential for fungal filamentation, stress response, and also confers partial resistance to antifungal $\operatorname{drug}(\mathrm{s})$. The DDR48/ddr48 heterozygote mutant strain was susceptible to ITZ in a concentration-dependent manner (Dib et al., 2008). Noteworthy is that this mutant also showed hypersensitivity to hydrogen peroxide $\left(\mathrm{H}_{2} \mathrm{O}_{2}\right)$, a strong oxidant, which indicated there was a relationship between ITZ susceptibility and $\mathrm{H}_{2} \mathrm{O}_{2}$ hypersensitivity (Dib et al., 2008). Thus, it appears that the cellular antioxidant system in yeasts is involved in tolerance to AMB or ITZ.

Stress-signaling/response genes of fungal pathogens are known to play roles in virulence, pathogenesis and defense against oxidative burst (rapid production of reactive oxygen species, ROS) from the host (Washburn et al., 1987; Hamilton and Holdom, 1999; Clemons et al., 2002; de Dios et al., 2010). In fungi, stress signals resulting from oxidative stress are integrated into the upstream mitogen-activated protein kinase (MAPK) pathways, which ultimately regulate the downstream response genes detoxifying the stress (Miskei et al., 2009). In yeasts, such as Saccharomyces cerevisiae or Schizosaccharomyces pombe, the HOG MAPK system plays a key role in countering oxidative stress (Toone and Jones, 1998; Lee et al., 2002; Miskei et al., 2009). SakA and MpkC in Aspergillus fumigatus are orthologous proteins to Hoglp of S. cerevisiae 
(Xue et al., 2004; Reyes et al., 2006). The sakAs (sakA gene deletion) is an osmotic/oxidative stress sensitive mutant, while the $m p k C \Delta$ ( $m p k C$ gene deletion) is a mutant of the polyalcohol sugar utilization system (Xue et al., 2004; Reyes et al., 2006).

The A. flavus msnA is an orthologous gene of S. cerevisiae MSN2 that encodes a $\mathrm{C}_{2} \mathrm{H}_{2}$-type zinc-finger regulator, Msn2p. Msn2p is required for yeast cells to cope with a broad range of environmental and physiological stresses (Ruis and Schuller, 1995). Maximum induction of Msn2p-dependent genes, such as CTT1 (encoding a catalase), under osmotic/oxidative stress required Hoglp (O'Rourke et al., 2002; see Miskei et al., 2009 for review). We surmised MsnA in Aspergillus would also functionally interact with MAPKs such as SakA and/or MpkC. Recently, an A. flavus CA14msnA $\Delta$ mutant was generated (and also examined in this study). Deletion of the A. flavus $m s n A$ gene adversely affected the fungus, as manifested by (1) increased expression of oxidative stress defense genes in Aspergillus, and (2) increased levels of ROS in $m s n A \Delta$ mutant comparing to the parental strain (Chang et al., 2011).

Thus, it is quite evident that the fungal antioxidant system could serve as an effective antifungal target of redox-potent agents. Such agents could disrupt cellular redox homeostasis in fungi and serve as a means for controlling fungal pathogens (see also Smits and Brul, 2005; Jaeger and Flohe, 2006).

Redox-potent natural phenolics, such as benzaldehyde analogs, or sulfur-containing compounds can be potent redox-cyclers in microorganisms and inhibit microbial growth by interfering with cellular redox homeostasis and/or the function of redox-sensitive components (Guillen and Evans, 1994; Jacob, 2006). We reasoned that redox-potent natural compounds, which destabilize the fungal antioxidant system, could act as potent chemosensitizing agents when co-applied with oxidative stress drugs, such as AMB or ITZ. Redox-potent chemosensitizers and drugs can affect common cellular targets, i.e., the antioxidant system of fungi, which results in synergistic inhibition of fungal growth. Thus, chemosensitization could make the use of toxic antifungal drugs or fungicides more attractive as an antifungal therapeutic strategy (see also Ogita et al., 2006).

In this in vitro study, we attempted to develop a chemosensitization strategy for control of fungal pathogens. We focused on targeting the oxidative stress response system of fungi with redox-potent chemosensitizing agents. Research emphasis was on: (1) identification of the level of sensitivities of Aspergillus MAPK or $m s n A$ gene deletion mutants to oxidizing agents, conventional oxidative stress drugs, i.e., AMB and ITZ, or redox-potent phenolic compounds, (2) chemosensitization of antifungal drugs with redox-potent phenolic compounds in Aspergillus and yeast pathogens (Candida, Cryptococcus), and (3) identification of complex III of mitochondrial respiratory chain (MRC) as an alternative oxidative stress target for control of yeast pathogens.

\section{MATERIALS AND METHODS FUNGAL STRAINS AND CULTURE CONDITIONS}

Aspergillus fumigatus AF293, wild type, and A. fumigatus MAPK gene deletion mutants ( $\operatorname{sakA\Delta }$ and $m p k C \Delta$ ) were grown at $35^{\circ} \mathrm{C}$ on potato dextrose agar (PDA) or Sabouraud dextrose agar (SDA; Sigma, St. Louis, MO, USA). A. terreus UAB673, UAB680, and
UAB698 (clinical isolates) were procured from Centers for Disease Control and Prevention, Atlanta, GA, USA, and were grown at $35^{\circ} \mathrm{C}$ on PDA or SDA. A. flavus NRRL3357, procured from the National Center for Agricultural Utilization Research, USDA-ARS, Peoria, IL, USA, was grown at $35^{\circ} \mathrm{C}$ on PDA or SDA. Also, A. flavus CA14 (parental strain) and CA14msnA $\triangle$ (knockout mutant for $m s n A$ gene; Chang et al., 2011) strains were grown at $28^{\circ} \mathrm{C}$ on PDA.

C. albicans 90028 and C. krusei 6258 (reference strains) were procured from American Type Culture Collection (Manassas, VA, USA). C. albicans CAN276, C. krusei CAN75, C. tropicalis CAN286 and Cryptococcus neoformans CN24 (clinical isolates) were procured from Instituto de Higiene e Medicina Tropical/CREM, Universidade Nova de Lisboa, Portugal. S. cerevisiae

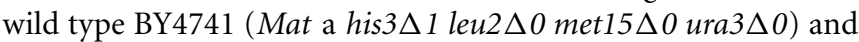
selected single gene deletion mutants, i.e., cytosolic superoxide dismutase (SOD; Cu, Zn-SOD; sod1 $\Delta$ ) mutant, mitochondrial SOD (Mn-SOD; sod $2 \Delta)$ mutant, antioxidative transcription factor mutant (yap1 $\Delta)$, glutathione reductase mutant $(g l r 1 \Delta)$, vacuolar $\mathrm{H}^{+}$-ATPase (V-ATPase) assembly mutant $(v p h 2 \Delta)$ and V-ATPase subunit A mutant (vma1 $\Delta)$, were procured from Open Biosystems [Huntsville, AL, USA; see Saccharomyces Genome Database (www.yeastgenome.org; accessed February 2, 2012)]. Yeast strains were cultured on synthetic glucose (SG; Yeast nitrogen base without amino acids $0.67 \%$, glucose $2 \%$ with appropriate supplements: uracil $0.02 \mathrm{mg} \mathrm{mL}^{-1}$, amino acids $0.03 \mathrm{mg} \mathrm{mL}^{-1}$ ) agar, yeast peptone dextrose (YPD; Bacto yeast extract $1 \%$, Bacto peptone $2 \%$, glucose $2 \%$ ) agar or SDA at $30^{\circ} \mathrm{C}$ for $S$. cerevisiae or $35^{\circ} \mathrm{C}$ for yeast pathogens (Candida, Cryptococcus), respectively.

\section{CHEMICALS}

Antifungal chemosensitizing agents [2,3-dihydroxybenzaldehyde (2,3-DHBA), salicylaldehyde (SA), thymol (THY)], antifungal drugs [antimycin A (AntA), amphotericin B (AMB), itraconazole (ITZ)], strobilurins [pyraclostrobin (PCS), kresoxim methyl (Kre$\mathrm{Me})$ ], and oxidizing agents [tert-butyl hydroperoxide $(t-\mathrm{BuOOH})$, hydrogen peroxide $\left(\mathrm{H}_{2} \mathrm{O}_{2}\right.$; Sigma product No. H1009, contained stabilizer)] were procured from Sigma Co. Hydrogen peroxide stock was prepared based on molar concentration provided by the manufacturer. Each compound was dissolved in dimethyl sulfoxide (DMSO; absolute DMSO amount: $<1 \%$ in media), except oxidizing agents, which were dissolved in water, before incorporation into culture media. In all tests, control plates (i.e., "No treatment") contained DMSO at levels equivalent to that of cohorts receiving antifungal agents, within the same set of experiments.

\section{ANTIFUNGAL BIOASSAY}

\section{Agar plate bioassay: filamentous fungi}

In the plate bioassay, measurement of sensitivities of filamentous fungi to the antifungal agents was based on percent (\%) radial growth of treated compared to control ("No treatment") fungal colonies (see text for test concentrations; Vincent, 1947). Minimum inhibitory concentration (MIC) values on agar plates were determined based on triplicate (except duplicate for $A$. flavus CA14 and CA14msnA $\Delta$ mutant) assays, and defined as the lowest concentration of agents where no fungal growth was visible on the plate. For the above assays, fungal conidia $\left(5 \times 10^{4} \mathrm{CFU} \mathrm{mL}^{-1}\right)$ were diluted in phosphate-buffered saline (PBS) and applied as 
a drop onto the center of PDA or SDA plates with or without antifungal compounds. Growth was observed for 3-7 days, except A. flavus CA14msnA $\Delta$ mutant (and A. flavus CA14 as a control), which needed around 3 weeks for optimal growth to determine cellular responses to drugs/compounds.

\section{Agar plate bioassay: yeasts}

Petri plate-based yeast dilution bioassays were performed with the $S$. cerevisiae wild type and mutant [antioxidant $(\operatorname{sod} 1 \Delta, \operatorname{sod} 2 \Delta$, $g l r 1 \Delta, y a p 1 \Delta)$, vacuolar $(v p h 2 \Delta, v m a 1 \Delta)]$ strains to assess the effects of THY on the antioxidant or vacuolar system of fungi. Yeast strains were exposed to $0.2-1.4 \mathrm{mM}$ of THY. This assay was performed in duplicate on SG agar following previously described protocols (Kim et al., 2008a). S. cerevisiae strains were grown at $30^{\circ} \mathrm{C}$ for 3-7 days.

Petri plate-based yeast dilution bioassays were also performed with the yeast pathogens (Candida and Cryptococcus) to investigate (1) the level of sensitivity of pathogens to ITZ or $t-\mathrm{BuOOH}$ (see text for concentrations), (2) sensitivities of pathogens to the inhibitors of complex III of MRC $\left(100 \mu \mathrm{g} \mathrm{mL}^{-1}\right)$, i.e., AntA, Kre-Me, and PCS (see Chemicals above), and (3) the chemosensitizing activity of 2,3-DHBA to PCS in yeast pathogens. For the chemosensitization test, yeast pathogens were exposed to $100 \mu \mathrm{g} \mathrm{mL}^{-1}$ of MRC inhibitors without or with $0.1-0.4 \mathrm{mM}$ of 2,3-DHBA. Yeast pathogens were grown on SG agar (in duplicate as described above for S. cerevisiae) at $35^{\circ} \mathrm{C}$ for 3-7 days.

\section{Microtiter plate (microdilution) bioassay: filamentous fungi}

To determine antifungal MICs and/or chemosensitizing activities of natural compounds $(0.1,0.2,0.4,0.8,1.6,3.2,6.4 \mathrm{mM})$ to antifungal drugs (AMB or ITZ; 0.125, 0.25, 0.5, 1, 2, 4, 8, $\left.16,32 \mu \mathrm{g} \mathrm{mL}^{-1}\right)$ in filamentous fungi, triplicate checkerboard bioassays $\left(0.4 \times 10^{4}\right.$ to $\left.5 \times 10^{4} \mathrm{CFU} \mathrm{mL}^{-1}\right)$ were performed in microtiter wells using a broth microdilution, according to modified methods outlined by the Clinical Laboratory Standards Institute (CLSI) M38-A (CLSI, 2008). MICs for chemosensitization were defined as the concentrations where no fungal growth was visible at 48 and $72 \mathrm{~h}$.

\section{Microtiter plate (microdilution) bioassay: yeasts}

Chemosensitizing activities of natural compounds $(0.1,0.2,0.4$, $0.8,1.6,3.2,6.4 \mathrm{mM}$ ) to antifungal drugs (AMB or ITZ; 0.125, 0.25, $0.5,1,2,4,8,16,32 \mu \mathrm{g} \mathrm{mL}^{-1}$ ) were determined by using checkerboard bioassays in microtiter plates (with RPMI 1640 medium; Sigma Co.). To determine changes in MICs of antifungal agents (i.e., drugs and chemosensitizers) in microtiter wells, triplicate assays $\left(0.5 \times 10^{5}\right.$ to $\left.2.5 \times 10^{5} \mathrm{CFU} \mathrm{mL}^{-1}\right)$ were performed using broth microdilution protocols according to modified methods outlined by the European Committee on Antimicrobial Susceptibility Testing (EUCAST; Cuenca-Estrella et al., 2003). MICs for chemosensitization were defined as the concentrations where no fungal growth was visible at 24 and $48 \mathrm{~h}$.

\section{DETERMINATION OF CHEMOSENSITIZING ACTIVITY OF SA TO ITZ}

Determination of chemosensitizing activity of SA, a volatile benzaldehyde analog, to ITZ was performed in segmented Petri dishes (150 mm × 10 mm; VWR International Co., Radnor, PA, USA).
These dishes are divided into four, isolated sections, and each of two sections was supplied with $6 \mathrm{~mL}$ of SDA for fungal growth (without or with 1-7 $\mu \mathrm{g} \mathrm{mL}^{-1}$ of ITZ in SDA). Then, conidial suspensions of A. fumigatus AF293 $\left(5 \times 10^{4} \mathrm{CFU} \mathrm{mL}^{-1}\right)$ were diluted in PBS and applied as a drop on the center of each section, providing two fungal inocula within each plate; see also Figure 3.).

SA was dissolved in DMSO, and was applied onto a round Whatman ${ }^{\mathrm{TM}}$ paper $(2.5 \mathrm{~cm}$ in diameter; GE Healthcare Bio-science Co., Piscataway, NJ, USA; Final volume: Total $150 \mu \mathrm{L}$ of SA plus DMSO on a Whatman ${ }^{\mathrm{TM}}$ paper per each plate based on SA concentration tested). Each SA preparation was then placed onto an empty section located between the fungal inocula. The fungal spores inside the Petri plate would be exposed to the volatilized SA. The SA-wet (or DMSO-wet control) Whatman ${ }^{\mathrm{TM}}$ paper was placed onto a piece of Parafilm ${ }^{\otimes}$ (American National Can Co., Chicago, IL, USA) to avoid the direct contact of SA plus DMSO with the surface of a Petri dish. The plates containing SA (or DMSO control) and fungal inocula were then sealed with two layers of Parafilm $^{\circledR}$ to prevent escape of SA. The plates were incubated at $35^{\circ} \mathrm{C}$ (5-7 days). The antifungal treatments, therefore, consist of (1) control plates: A. fumigatus AF293 inocula without SA vapor (DMSO only) and (2) treated plates: A. fumigatus AF293 inocula with SA vapor (9.5-95 mM on a Whatman ${ }^{\mathrm{TM}}$ paper). Results were based on two replicated plates.

\section{RESULTS \\ ASPERGILLUS MAPK AND msnA MUTANTS WERE SENSITIVE TO OXIDATIVE STRESS}

We initially investigated the phenotypic responses (i.e., level of sensitivity) of three Aspergillus mutant strains, i.e., deletion mutants for A. fumigatus MAPKs, sakA and $m p k C$, and A. flavus $m s n A$ genes, to $t$ - $\mathrm{BuOOH}$ (an organic peroxide) and $\mathrm{H}_{2} \mathrm{O}_{2}$ (hydrogen peroxide). Sensitivities of fungi to the oxidizing agents were determined based on relative fungal radial growth on agar plates. The sakA $\Delta, m p k C \Delta$ and $m s n A \Delta$ mutants currently available were derived from two different species of infectious Aspergillus. However, we reasoned that results presented in this study would provide the basis for detecting signaling network(s) in Aspergillus, in general, under the stress/toxicity triggered by oxidizing agents and/or antifungal drugs. To our knowledge, the A. flavus $m s n A$ is the first MSN2 gene ortholog functionally characterized (with gene knockout) in Aspergillus.

In our tests, all three Aspergillus mutants, i.e., A. fumigatus sakA $\Delta$ and $m p k C \Delta$, A. flavus CA14msnA $\Delta$, showed marginally higher sensitivity to $t$ - $\mathrm{BuOOH}$ and $\mathrm{H}_{2} \mathrm{O}_{2}$ compared to the wild type strains (Data not shown). Based on these results, we postulated that $m s n A$ (downstream regulator) and sakA/mpkC (upstream MAPKs) are located in the same stress response network in Aspergillus under the peroxide-mediated oxidative stress.

\section{ANTIOXIDANT MUTANTS WERE SENSITIVE TO TOXICITIES OF AMB AND ITZ}

Next, we examined the level of sensitivity of Aspergillus mutants to ITZ or AMB in plate bioassays. We tried to determine if the function of the fungal antioxidant system is responsive to toxicities triggered by ITZ or AMB. As shown in Figure 1, the A. fumigatus 


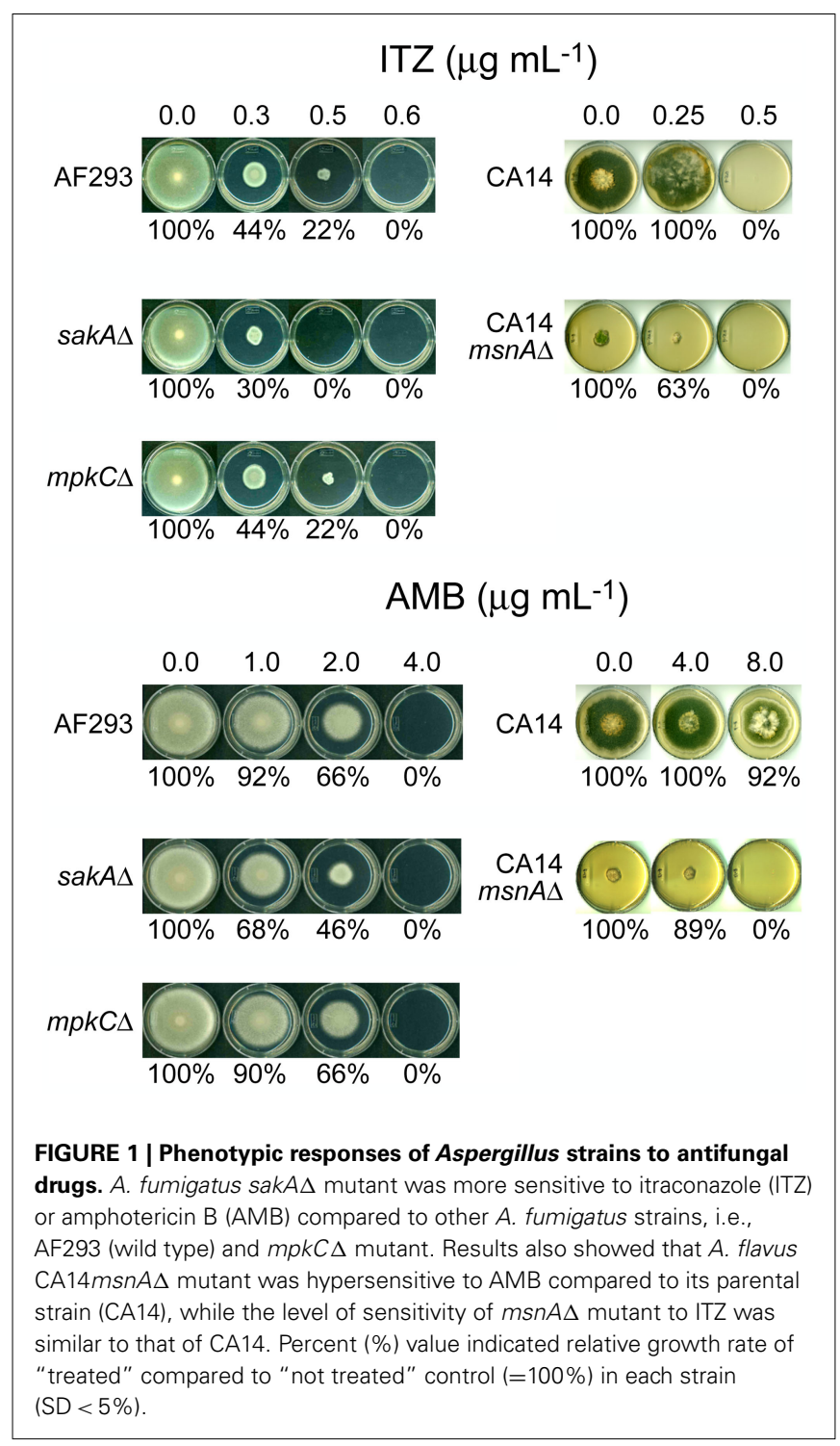

sakA $\triangle$ mutant showed higher sensitivity to ITZ or AMB compared to $A F 293$ or the $m p k C \Delta$ mutant. The $A$. fumigatus sakA $\Delta$ mutant did not grow at $0.5 \mu \mathrm{g} \mathrm{mL}^{-1}$ of ITZ (i.e., sensitive), while AF293 and the $m p k C \Delta$ mutant did grow (Figure 1). Also, the A. fumigatus sak $A \Delta$ mutant was more sensitive to AMB compared to the AF293 or $m p k C \Delta$ strains. For example, when treated with AMB, the inhibition rate of fungal growth for the sakA $\Delta$ mutant was $32-54 \%$ (i.e., more sensitive; $\mathrm{SD}<5 \%$ ) at $1.0-2.0 \mu \mathrm{g} \mathrm{mL}^{-1}$ of $\mathrm{AMB}$, while inhibition of AF293 or the mpkC $\Delta$ mutant was around $8-34 \%$ ( $\mathrm{SD}<5 \%$; Figure 1 ).

To evaluate the negative impact of the deletion of MAPK genes on cell survivability after AMB or ITZ treatment, we also monitored the minimum fungicidal concentrations (MFCs) of AMB or ITZ for A. fumigatus AF293, sakA $\Delta$ and $m p k C \Delta$ strains in a separate microdilution (microtiter plate) bioassay. Fungi were treated with 1-128 or $1-64 \mu \mathrm{g} \mathrm{mL}^{-1}$ of AMB or ITZ, respectively. In this test, over $99.9 \%$ of fungicidality was achieved in the A. fumigatus sakA $\triangle$ mutant at dosage levels of ITZ or AMB lower than
Table 1 | Levels of fungicidality of itraconazole (ITZ) or amphotericin B (AMB) at various concentrations against Aspergillus fumigatus strains (AF293, sakA $\Delta, m p k C \Delta)$.

\begin{tabular}{|c|c|c|c|}
\hline & \multicolumn{3}{|c|}{ Strains } \\
\hline & AF293 & $\operatorname{sak} A \Delta$ & $m p k C \Delta$ \\
\hline \multicolumn{4}{|c|}{ ITZ Conc. $\left(\mu \mathrm{g} \mathrm{mL}^{-1}\right)$} \\
\hline 1 & $N^{1}$ & $99.45 \%$ & ND \\
\hline 2 & ND & $99.85 \%$ & $99.65 \%$ \\
\hline 4 & ND & $99.89 \%$ & $99.72 \%$ \\
\hline 8 & ND & $99.92 \%$ & $99.76 \%$ \\
\hline 16 & $99.39 \%$ & $99.94 \%$ & $99.83 \%$ \\
\hline 32 & $99.42 \%$ & $99.95 \%$ & $99.83 \%$ \\
\hline 64 & $99.93 \%$ & $99.99 \%$ & $99.99 \%$ \\
\hline \multicolumn{4}{|c|}{ AMB Conc. $\left(\mu \mathrm{g} \mathrm{mL}^{-1}\right)$} \\
\hline 1 & ND & ND & ND \\
\hline 2 & ND & ND & ND \\
\hline 4 & ND & $99.95 \%$ & ND \\
\hline 8 & ND & $100.00 \%$ & ND \\
\hline 16 & $99.31 \%$ & $100.00 \%$ & $99.45 \%$ \\
\hline 32 & $99.43 \%$ & $100.00 \%$ & $99.68 \%$ \\
\hline 64 & $99.88 \%$ & $100.00 \%$ & $99.94 \%$ \\
\hline 128 & $99.95 \%$ & $100.00 \%$ & $99.98 \%$ \\
\hline
\end{tabular}

ND, not determined (<99.00\%).

Columns showing over $99.90 \%$ of fungicidality are indicated in bold.

that for AF293 or the $m p k C \Delta$ mutant (Table 1). Altogether, we concluded that the antifungal activity of AMB or ITZ evoked a cellular oxidative stress response requiring participation of MAPK pathway genes in A. fumigatus. However, SakA must play a more significant role in response to AMB or ITZ than MpkC, as represented by the higher sensitivity of sakA $\Delta$ than $m p k C \Delta$ to either drug. A similar type of hypersensitivity of the sak $A \Delta$ mutant was previously observed when it was treated with redox-potent phenolic reagents, where the $m p k C \Delta$ mutant showed less sensitivity to the same treatment (Kim et al., 2010).

Sensitivity of the A. flavus CA14msnA $\Delta$ mutant to AMB was also examined using plate bioassays. As shown in Figure 1, the MIC of the A. flavus CA14msnA $\triangle$ mutant for AMB was between 4.0 and $8.0 \mu \mathrm{g} \mathrm{mL}^{-1}$, while that of the parental strain, A. flavus CA14, was above $8.0 \mathrm{\mu g} \mathrm{mL}^{-1}$ (the highest concentration of AMB tested). However, unlike its response to AMB, there was no difference in level of sensitivity of the A. flavus CA14msnA $\triangle$ mutant and the parental strain to ITZ (i.e., MICs for both strains were between 0.25 and $0.5 \mu \mathrm{g} \mathrm{mL}^{-1}$; although, some discoloration of the parental strain occurred with ITZ treatment; Figure 1). One plausible explanation for this differential response to two different drugs would be that a regulator(s) other than MsnA is involved in fungal response/tolerance to ITZ.

Collectively, the experimental results from the A. fumigatus and A. flavus strains studied indicate that antifungal activity of ITZ or AMB involves the functioning/response of fungal antioxidant system. Among the molecular genetic components examined in these Aspergillus strains, it appears that SakA plays a more significant role for fungal tolerance/response to both ITZ- and AMB-induced toxicity than do either MpkC or MsnA. 


\section{A. FLAVUS msnA MUTANT WAS SENSITIVE TO REDOX-POTENT PHENOLIC COMPOUNDS}

In prior studies, the $A$. fumigatus sakA $\Delta$ mutant showed hypersensitivity to 2,3-DHBA or THY (Kim et al., 2008a,b). These compounds were effective as chemosensitizing agents to conventional antifungal drugs/fungicides (Kim et al., 2008a,b).

In the present study, the A. flavus CA14msnA $\Delta$ mutant was also more sensitive to 2,3-DHBA or THY compared to the parental strain in plate bioassays (Figure data not shown). For example, the MICs for 2,3-DHBA and THY were between 0.8 and $1.6 \mathrm{mM}$ or 3.2 and $6.4 \mathrm{mM}$, respectively, in the parental strain, while those of the $m s n A \Delta$ mutant were between 0.0 and $0.1 \mathrm{mM}$ or 0.2 and $0.4 \mathrm{mM}$, respectively. Therefore, including results with the $t-\mathrm{BuOOH}$ and $\mathrm{H}_{2} \mathrm{O}_{2}$ experiments (see above), these findings with 2,3-DHBA and THY further provide evidence of antioxidative cellular components (i.e., MAPKs and MsnA) playing a role in fungal response to drugs (ITZ, AMB) or redox-potent compounds (2,3-DHBA, THY) [see Table 2 for the summary of responses of Aspergillus MAPKs (sakA $\Delta, m p k C \Delta$ ) and $m s n A \Delta$ mutants to the test compounds].

\section{REDOX-POTENT PHENOLIC COMPOUNDS ACT AS CHEMOSENSITIZERS TO ANTIFUNGAL DRUGS IN FILAMENTOUS FUNGI}

We next investigated the potential role of redox-potent compounds (2,3-DHBA, THY) as chemosensitizing agents to oxidative stress drugs (AMB, ITZ) in different fungal pathogens. SA was also included in these tests. We reasoned there should be either an additive or synergistic antifungal interaction if the drug and compounds were co-applied, lowering dosages for control of fungi than sole treatment of each drug. At this stage of study, we tried to identify the most effective chemosensitization strategy with various combinations of redox-potent compounds and antifungal drugs.

\section{Chemosensitization of ITZ with THY}

First, we performed a yeast dilution bioassay on SG agar containing THY (0.2-1.4 mM), using a number of different $S$. cerevisiae gene deletion mutants (see Fungal Strains and Culture Conditions). As shown in Figure 2, vacuolar [ $v p h 2 \Delta, v m a 1 \Delta$; "growth" at no dilution $\left(10^{0}\right)$ and $10^{1}$ dilution spots only] and antioxidant $\left(\operatorname{sod} 2 \Delta, \operatorname{sod} 1 \Delta, \operatorname{glr} 1 \Delta\right.$; "growth" at no dilution, $10^{1}$ and/or $10^{2}$ dilution spots only) mutants exhibited higher sensitivity to THY $(0.8 \mathrm{mM})$ compared to the wild type ("growth" from no dilution to $10^{4}$ dilution). These results indicated that, like carvacrol (a structural isomer of THY; Rao et al., 2010), THY disrupted cellular ion and also redox homeostasis in fungi. The vacuolar mutants appeared to be more sensitive to THY compared to the antioxidant mutants. The yap1 1 , an antioxidative transcription factor mutant, was sensitive to THY but less so than the other antioxidant mutants examined.

Next, we examined the chemosensitizing efficacy of THY to ITZ in five different Aspergillus strains using microdilution bioassays. As shown in Table 3, co-application of THY and ITZ enhanced the antifungal efficacy of either compounds. Namely, MICs of THY and ITZ were lowered under co-application compared to independent treatment of each compound, alone, in most fungi. Fungal response to chemosensitization (i.e., THY plus ITZ) was strain dependent, where A. fumigatus AF293 was the most sensitive/responsive strain (i.e., both MIC and MFC were lowered), while A. flavus 3357 was the least affected by chemosensitization [i.e., no effect on MIC or MFC (data not shown)].

\section{MsnA as an effective target of chemosensitization: $A M B$ with 2,3-DHBA}

First, chemosensitization of fungi by 2,3-DHBA to AMB (see Microtiter Plate (Microdilution) Bioassay: Filamentous Fungi for concentrations) was investigated in five Aspergillus strains using microdilution bioassays. All the compound interactions between 2,3-DHBA and AMB were additive $(0.6 \leq \mathrm{FICI} \leq 1.0)$, depending on Aspergillus strain (Data not shown). However, no

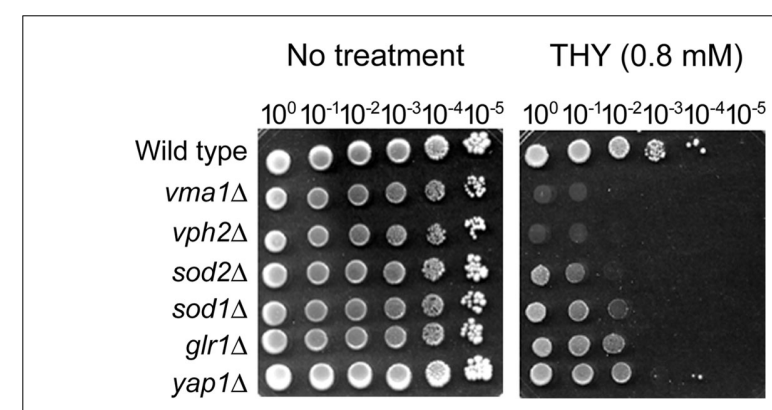

FIGURE 2 | Yeast dilution bioassay showing the sensitive response of Saccharomyces cerevisiae gene deletion mutants, i.e., vacuolar $(v p h 2 \Delta, v m a 1 \Delta)$ and antioxidant $(\operatorname{sod} 2 \Delta, \operatorname{sod} 1 \Delta, \operatorname{glr1} \Delta, \operatorname{yap} 1 \Delta)$, to thymol (THY). Although few colonies of yap1 $\Delta$ mutant appeared at the dilution spots $10^{-3}$ and $10^{-4}$, where the wild type colonies also appeared, yap1 $1 \Delta$ mutant was also considered to be sensitive to THY. Results shown are representative data from treatment with $0.8 \mathrm{mM}$ of THY.

Table 2 | Summary of sensitivities of Aspergillus MAPKs ( $\operatorname{sakA} \Delta, m p k C \Delta$ ) and $m s n A \Delta$ mutants to the test compounds. ${ }^{1}$

\begin{tabular}{lllllc}
\hline Strains & \multicolumn{5}{c}{ Compounds } \\
\cline { 2 - 6 } & $\boldsymbol{t}$-BuOOH & $\mathbf{H}_{\mathbf{2}} \mathbf{O}_{\mathbf{2}}$ & AMB & ITZ & 2,3-DHBA \\
\hline A. flavus msnAs & $\mathrm{S}$ & $\mathrm{S}$ & $\mathrm{S}$ & $\mathrm{N}$ & $\mathrm{S}$ \\
A. fumigatus sakAs & $\mathrm{S}$ & $\mathrm{S}$ & $\mathrm{S}$ & $\mathrm{S}$ & $\mathrm{S}$ \\
A. fumigatus $m p k C \Delta$ & $\mathrm{S}$ & $\mathrm{S}$ & $\mathrm{N}$ & $\mathrm{N}$ & $\mathrm{S}^{2}$ \\
\hline
\end{tabular}

${ }^{1} S$, sensitive; $N$, not sensitive (compared to the parental strains).

${ }^{2}$ Determined in previous studies (see Kim et al., 2008a,b). 
Table 3 | Chemosensitization of itraconazole (ITZ; $\mu \mathrm{g} \mathrm{mL}^{-1}$ ) with thymol (THY; mM) tested against pathogenic Aspergillus.

\begin{tabular}{llll}
\hline Strains & Compounds & MIC alone & MIC combined \\
\hline A. fumigatus AF293 & THY, ITZ & $0.4-0.8,2-4$ & $0.2-0.4,1-2$ \\
A. flavus NRRL3357 & THY, ITZ & $0.8-1.6,0.5-1$ & $0.8-1.6,0.5-1$ \\
A. terreus UAB673 & THY, ITZ & $1.6-3.2,0.5-1$ & $0.8-1.6,0.25-0.5$ \\
A. terreus UAB680 & THY, ITZ & $1.6-3.2,0.5-1$ & $0.8-1.6,0.25-0.5$ \\
A. terreus UAB698 & THY, ITZ & $0.8-1.6,0.5-1$ & $0.4-0.8,0.25-0.5$ \\
\hline Strain & Compounds & MFC alone & MFC combined \\
\hline A. fumigatus AF293 & THY, ITZ & $1.6-3.2,>16^{3}$ & 1.0 \\
\hline
\end{tabular}

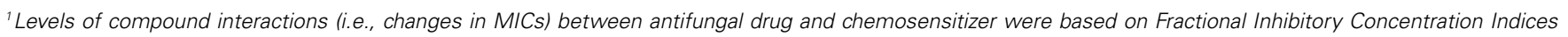

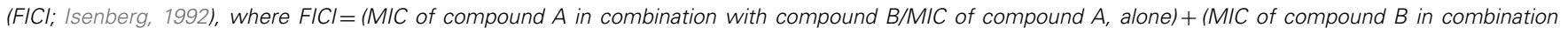

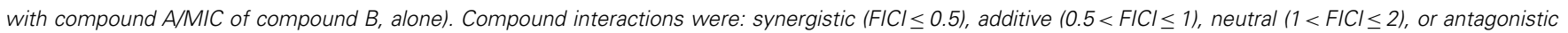

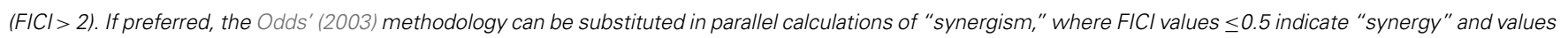
$>0.5-4$ indicate "indifference."

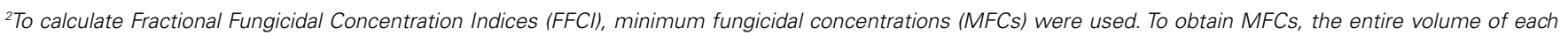

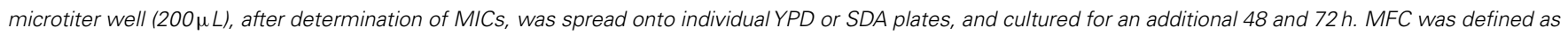

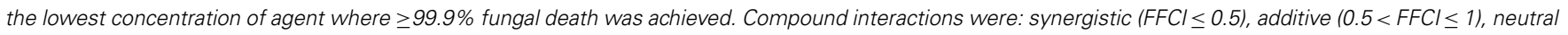

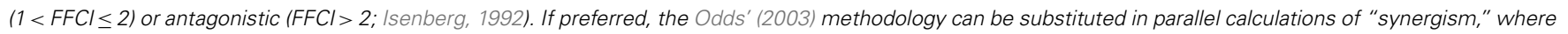
FFCl values $\leq 0.5$ indicate "synergy" and values $>0.5-4$ indicate "indifference."

${ }^{3}$ For calculation (FFCl) purpose, $32 \mu \mathrm{g} \mathrm{mL}^{-1}$ (doubling of $16 \mu \mathrm{g} \mathrm{mL}^{-1}$ ) was used.

chemosensitization was detected for lowering MFCs in all fungi tested (data not shown), indicating the efficacy of chemosensitization by using 2,3-DHBA plus AMB was at the level of lowering MICs of each agent, only.

Meanwhile, in separate plate bioassays, we exposed A. flavus CA14 (parental strain) and the A. flavus CA14msnA $\Delta$ mutant to 2,3-DHBA plus AMB. Co-application of AMB $\left(2 \mu \mathrm{g} \mathrm{m}^{-1}\right)$ and 2,3-DHBA at $20 \mu \mathrm{M}$ (which is a much lower concentration compared to that used in the microdilution bioassay above) completely inhibited the growth of the A. flavus CA14msnA $\Delta$ mutant, while independent treatment of each compound, at these concentrations alone, allowed full (with 2,3-DHBA) to slightly sensitive (with AMB) growth of this mutant (Data not shown). However, almost no chemosensitization was achieved in the parental strain under the same condition (Data not shown). Thus, it appears that $m s n A$ could be an effective antifungal target of redox-potent drugs/compounds, where disruption of its function enhanced the antifungal interaction between 2,3-DHBA and AMB.

\section{Chemosensitization of ITZ with SA}

We examined the chemosensitizing efficacy of SA, a volatile benzaldehyde analog, to ITZ in A. fumigatus AF293 in plate bioassays. We reasoned that the volatile characteristic of SA would facilitate the development of targeted delivery of this compound to the infection site, such as pulmonary aspergillosis. Previously, the growth of Aspergillus was inhibited up to $10-75 \%$ by coapplication of volatilized SA with either AntA or strobilurin, both inhibitors of complex III in the MRC (Kim et al., 2011a). We identified the fungal antioxidant system as one of the molecular targets of SA, where the model yeast $S$. cerevisiae $\operatorname{sod} 1 \Delta, \operatorname{sod} 2 \Delta, \operatorname{glr} 1 \Delta$, and $v p h 2 \Delta$ mutants showed hypersensitivity to SA (Kim et al., 2011a).
As shown in Figure 3, combined application of volatile SA (at $37.5-45.0 \mathrm{mM})$ and ITZ $\left(2-3 \mu \mathrm{g} \mathrm{mL}^{-1}\right.$, incorporated into SDA media) completely inhibited the growth of A. fumigatus AF293, while individual treatment of each compound, alone, allowed fungal growth. Therefore, like the chemosensitization of SA to the MRC inhibitors (Kim et al., 2011a), volatilized SA also enhanced the antifungal activity of ITZ as a chemosensitizing agent of $A$. fumigatus.

\section{CORRELATION BETWEEN ITZ AND $t$-BuOOH SENSITIVITIES IN CANDIDA AND CRYPTOCOCCUS}

Since positive correlation between the level of drug/compound sensitivity and antioxidation capacity was identified in the filamentous fungi (see above), we also investigated if such a relationship occurred in yeast pathogens using ITZ and $t-\mathrm{BuOOH}$. As shown in Figure 4, C. albicans 90028, CAN276, C. krusei CAN75, and C. tropicalis CAN286 were relatively more tolerant (i.e., growth up to the $10^{5}$ dilution spot) to ITZ compared to C. krusei 6258 and C. neoformans CN24 (i.e., growth at no cellular dilution only). Noteworthy is that C. krusei 6258 and C. neoformans $\mathrm{CN} 24$, two ITZ-sensitive strains, were also sensitive to $t$ - $\mathrm{BuOOH}$ (Figure 4). This finding indicated there might be a connection between ITZ sensitivity and antioxidation capacity in yeast pathogens [Our recent data with yeast pathogens also indicated the positive correlation between AMB sensitivity (of C. albicans CAN276) and thiol-oxidant sensitivity (Manuscript submitted)].

\section{REDOX-POTENT PHENOLIC COMPOUNDS ACT AS CHEMOSENSITIZERS TO ANTIFUNGAL DRUGS IN YEAST PATHOGENS Chemosensitization of $A M B$ with $T H Y$}

We examined the chemosensitizing efficacy of THY to AMB in six different yeast pathogens. As shown in Table 4, most of the compound interactions (FICI) between THY and AMB were additive, 
except for C. neoformans $\mathrm{CN} 24$, which was a neutral interaction. The level of MFC was also lowered in C. albicans CAN276 and C. krusei CAN75, where the FFCI was determined as additive and synergistic, respectively. Whereas, no chemosensitization was

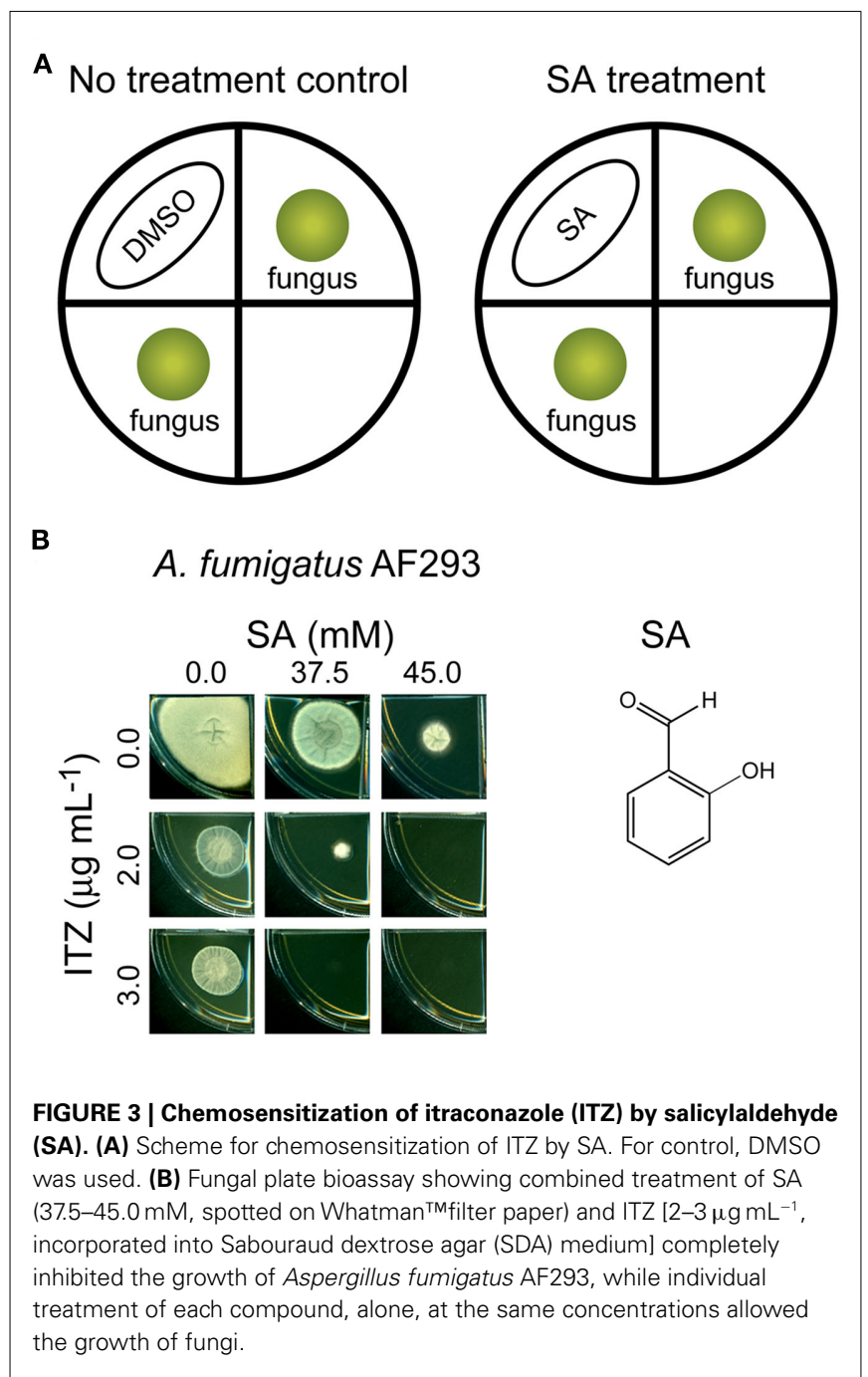

achieved in other strains for lowering the MFCs. We concluded that C. albicans CAN276 and C. krusei CAN75 were the most sensitive/responsive strains for this chemosensitization.

\section{Chemosensitization of ITZ with 2,3-DHBA}

Next, we investigated the chemosensitizing activity of 2,3-DHBA to ITZ (see Microtiter Plate (Microdilution) Bioassay: Yeasts for concentrations) in yeast pathogens. The compound interactions (FICI) between the two compounds in C. albicans 90028, CAN276 and $C$. tropicalis CAN286 were synergistic to additive $(0.5 \leq$ FICI $\leq 0.6)$, while those of the remaining yeasts were neutral (Data not shown). No chemosensitization was achieved in any of the strains for lowering MFCs, indicating that, compared to other chemosensitization tests (see above), co-application of 2,3DHBA and ITZ resulted in limited chemosensitizing efficacy, i.e., chemosensitization in three yeast pathogens for lowering MICs only (Data not shown).

\section{INHIBITION OF COMPLEX III OF THE MRC: ALTERNATIVE OXIDATIVE STRESS TARGET FOR CONTROL OF YEAST PATHOGENS}

We examined the antifungal efficacy of three inhibitors of complex III of the MRC, i.e., AntA and strobilurins (Kre-Me, PCS), in four clinical yeast isolates to investigate whether yeast pathogens could

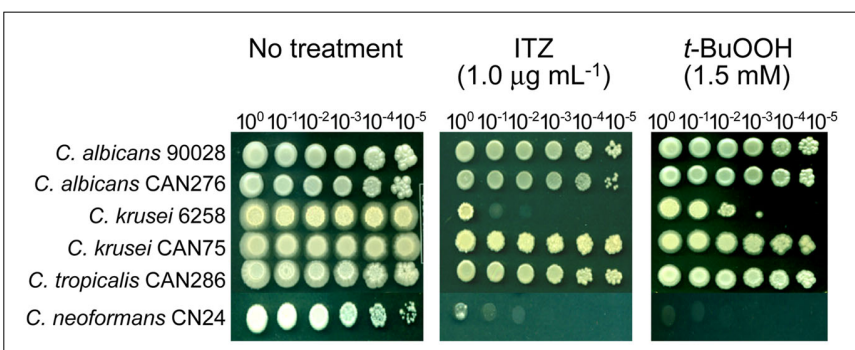

FIGURE 4 | Phenotypic responses of yeast pathogens to itraconazole (ITZ) and tert-butyl hydroperoxide ( $t$-BuOOH). Results showed that Candida krusei 6258 and Cryptococcus neoformans CN24, two ITZ-sensitive strains, were also sensitive to $t$ - $\mathrm{BuOOH}$, indicating the correlation between ITZ toxicity and oxidative stress. Results shown here are representative data from the treatment with $1.0 \mu \mathrm{g} \mathrm{mL}^{-1}$ of ITZ and $1.5 \mathrm{mM}$ of $t-\mathrm{BuOOH}$, respectively.

Table 4 | Chemosensitization of amphotericin B (AMB; $\mu \mathrm{g} \mathrm{mL}^{-1}$ ) with thymol (THY; $\mathrm{mM}$ ) tested in yeast pathogens.

\begin{tabular}{lllc}
\hline Strains & Compounds & MIC alone & MIC combined \\
\hline C. albicans ATCC 90028 & FHY, AMB & $0.8-1.6,1-2$ & $0.4-0.8,0.125-0.25$ \\
C. albicans CAN276 & THY, AMB & $0.8-1.6,0.5-1$ & $0.4-0.8,0.125-0.25$ \\
C. tropicalis CAN286 & THY, AMB & $0.8-1.6,1-2$ & $0.4-0.8,0.25-0.5$ \\
C. krusei ATCC 6258 & THY, AMB & $0.8-1.6,1-2$ & $0.4-0.8,0.5-1$ \\
C. krusei CAN75 & THY, AMB & $0.8-1.6,1-2$ & $0.4-0.8,0.5-1$ \\
Cryptococcus neoformans CN24 & THY, AMB & $0.4-0.8,1-2$ & $0.4-0.8,1-2$ \\
Strains & Compounds & MFC alone & MFC combined \\
\hline C. albicans CAN276 & THY, AMB & $0.8-1.6,1-2$ & 0.0 \\
C. krusei CAN75 & THY, AMB & $1.6-3.2,2-4$ & $0.4-0.8,0.5-1$ \\
\hline
\end{tabular}

1,2 See footnotes of Table 3 for calculations. 
also be chemosensitized by 2,3-DHBA to increase vulnerability to the complex III inhibitors.

As shown in Figure 5A (i.e., yeast dilution bioassay on SG agar containing $100 \mu \mathrm{g} \mathrm{mL}^{-1}$ of MRC inhibitors), C. neoformans CN24 was relatively more innately sensitive to the MRC inhibitors compared to other pathogens. Results indicated disruption of complex III of MRC, alone, could be an effective strategy for control of $C$. neoformans $\mathrm{CN} 24$. The remaining three pathogens, relatively tolerant to the complex III inhibitors, were further examined for chemosensitization with 2,3-DHBA in plate bioassays.

Disruption of complex III of the MRC results in an abnormal release of electrons that additionally damage cellular components by oxidative stress (Takimoto et al., 1999). Therefore, antioxidant enzymes, such as Mn-SOD, play important roles in protecting cells from oxidative damage caused by MRC inhibitors. However, when fungal cells are treated with redox-potent chemosensitizers, cellular demand for Mn-SOD will continuously increase as more and more oxidative stress is applied. In this situation, the levels of antioxidant capacity in fungi, such as antioxidant enzymes, would not be sufficient for detoxifying the concerted activities of multiple oxidative stressors (e.g., MRC inhibitors/oxidative stress drug + redox-potent chemosensitizer), resulting in increased inhibition of fungal growth. Hence, we surmised redox-potent benzaldehydes could be useful chemosensitizing agents also in yeast pathogens when co-applied with the complex III inhibitors of the
MRC. We used 2,3-DHBA as a representative molecule for this chemosensitization.

As shown in Figure 5B, co-application of 2,3-DHBA (0.1 mM) and PCS $\left(100 \mu \mathrm{g} \mathrm{mL}^{-1}\right)$ enhanced growth inhibition of C. albicans CAN276 and C. tropicalis CAN286 compared to the control, while C. krusei CAN75 maintained robust growth under the same condition. Thus, C. krusei CAN75 seemed to be more tolerant to chemosensitization by 2,3-DHBA (A relatively lackluster response of C. krusei CAN75 to 2,3-DHBA chemosensitization was also observed above, with ITZ). However, slight enhancement [i.e., a 10 -fold increase in number of yeast cells needed to survive (one cellular dilution less)] of growth inhibition of C. krusei CAN75 was achieved by increasing the concentration of 2,3-DHBA to $0.4 \mathrm{mM}$ (see Figure 5B). In summary, these results indicated that: (1) The MRC (e.g., complex III) could be an alternative oxidative stress target for yeast pathogens, (2) Benzaldehyde analogs, such as 2,3-DHBA, could be developed as potent chemosensitizers in yeasts, especially with MRC inhibitors, and (3) Fungal sensitivity to chemosensitization (i.e., with 2,3-DHBA plus PCS), is strain specific, wherein C. krusei CAN75 was least sensitive.

\section{DISCUSSION}

Cellular antioxidant systems of fungi appear to be promising targets of redox-potent natural phenolics for control of fungal pathogens. The natural phenolics studied, in vitro, targeted MAPK
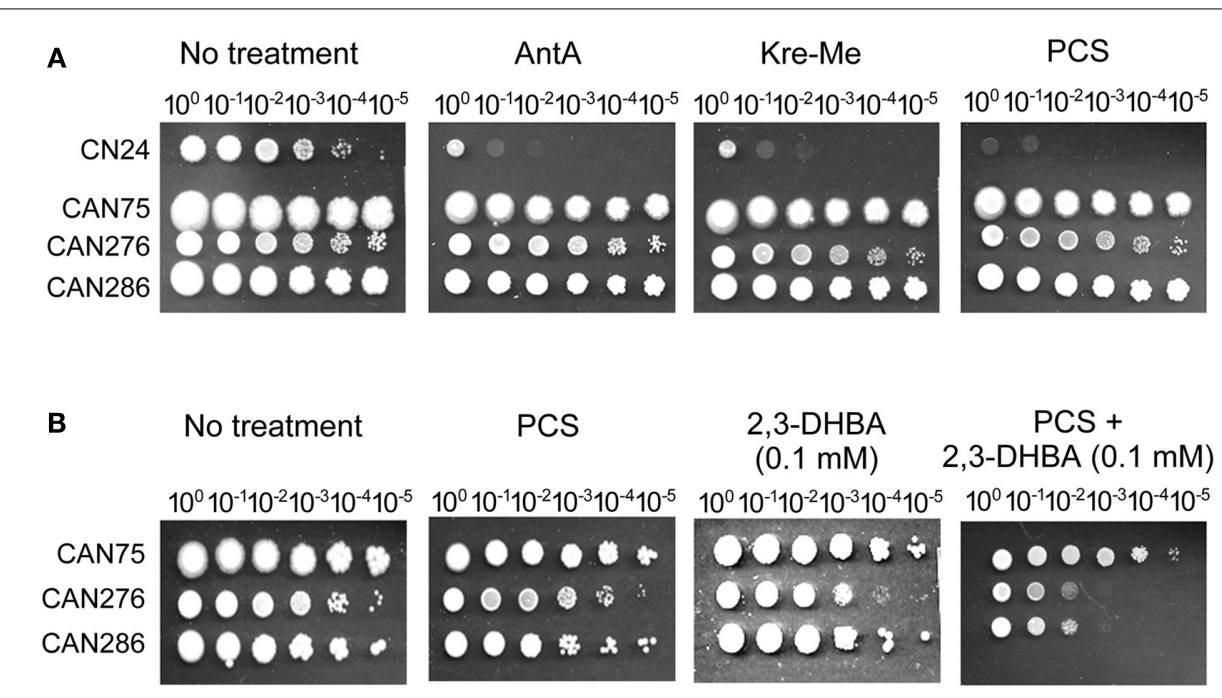

$\mathrm{PCS}+$

2,3-DHBA

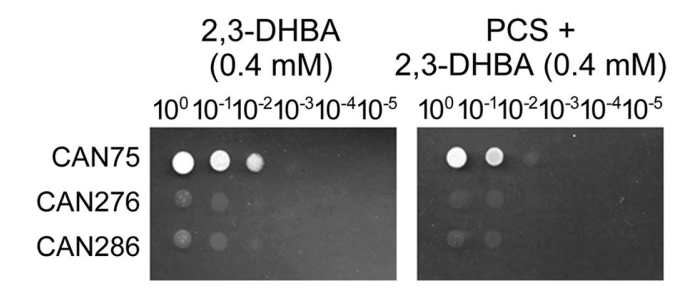

FIGURE 5 | Chemosensitization of pyraclostrobin (PCS), an inhibitor for complex III in mitochondrial respiratory chain (MRC) with

CAN276, C. krusei CAN75, C. tropicalis CAN286). (B) Co-application of 2,3-DHBA $(0.1 \mathrm{mM})$ and PCS $\left(100 \mu \mathrm{g} \mathrm{mL}^{-1}\right)$ enhanced the inhibition of the growth of $C$. albicans CAN276 and C. tropicalis CAN286, while similar type of growth inhibition of $C$. krusei CAN75 could be achieved by increasing the concentration of 2,3-DHBA up to $0.4 \mathrm{mM}$. 
signaling and/or the antioxidant enzymes, $\mathrm{Cu}, \mathrm{Zn}-\mathrm{SOD}, \mathrm{Mn}-\mathrm{SOD}$, or glutathione reductase. THY further targeted the vacuolar system, such as VPH2 and VMA1, as examined in S. cerevisiae. Also, THY or benzaldehyde analogs, such as 2,3-DHBA and SA, can be used as potent chemosensitizing agents to enhance antifungal activity of AMB, ITZ, or PCS.

A. fumigatus MAPK (sakA, mpkC) and A. flavus msnA gene deletion mutants were sensitive to organic and hydrogen peroxides. This common sensitivity indicates that $m s n A$, a gene regulator downstream of the MAPKs sakA and $m p k C$, and these MAPKs, are all located in the same stress response network under $t-\mathrm{BuOOH}$ or $\mathrm{H}_{2} \mathrm{O}_{2}$ stress. Also confirmed was that oxidative stress is one of the contributing mechanisms of toxicities of AMB and ITZ in fungal pathogens. In A. fumigatus, SakA appeared to play a more important role for fungal tolerance to ITZ and/or AMB than MpkC, the deletion mutant of which was relatively insensitive to these drugs. Meanwhile, in the yeast pathogens, ITZ-sensitive strains (i.e., C. krusei 6258, C. neoformans $\mathrm{CN} 24$ ) were also sensitive to $t$ $\mathrm{BuOOH}$. Thus, results indicated that the level of sensitivity (and/or tolerance) to oxidative stress drugs was correlated with the antioxidant capacity of fungal pathogens (both in ascomycetous and basidiomycetous fungi).

Involvement of stress response signaling systems in drug resistance has been previously documented in fungal pathogens. For example, the heat shock protein Hsp90, an essential molecular chaperone regulating cell signaling, was shown to govern azole drug resistance of C. albicans either in planktonic or biofilm conditions (LaFayette et al., 2010; Robbins et al., 2011). In the case of Hsp90, its inhibition/depletion resulted in reduction of calcineurin and the terminal cell wall integrity MAPK, Mkc1, in planktonic conditions, whereas marked decrease in matrix glucan levels occurred in biofilms (LaFayette et al., 2010; Robbins et al., 2011). The Mkc1-mediated pathway is also activated in response to oxidative stress (de Dios et al., 2010 and references therein). Like the SakA shown in our study, another Hog 1 pathway component, i.e., Hrk1 (Hog1-regulated kinase 1) of C. neoformans was recently shown to be involved in the response to azole drug treatment (Kim et al., 2011b). Also, ROS-inducing effect of miconazole, and involvement of SODs of C. albicans in biofilm persistence against miconazole (Vandenbosch et al., 2010; Bink et al., 2011) were recently reported, further demonstrating the role of fungal antioxidant system such as SODs in drug resistance.

We also found differences in effects of tested compounds depending upon (1) types of mutation in the antioxidant system (i.e., MsnA or MAPK gene deletions) and (2) types of drugs. For example, Aspergillus deletion mutants for sakA or $m s n A$ genes were hypersensitive to AMB (Figure 1), while the A. flavus msnA $\Delta$ mutant was less sensitive to ITZ compared to the A. fumigatus sakA $\Delta$ mutant. Presumably, regulator(s) other than MsnA might be involved in fungal response/tolerance to ITZ. Regarding the AMB sensitivity of both sakA $\Delta$ and $m s n A \Delta$ mutants of Aspergillus, S. cerevisiae could serve as a model for explaining their sensitive phenotype. In $S$. cerevisiae, functional interaction between the HOG signaling system and Msn2p (and Msn4p, which is a Msn2p analog) under oxidative stress has been well documented (Görner et al., 1998; O'Rourke et al., 2002 and references therein). Thus, functions of Hog1p and Msn2p/Msn4p are tightly linked under stress conditions. Considering SakA in A. fumigatus is an orthologous protein to Hog1p of S. cerevisiae, a similar phenomenon might also occur with the treatment of AMB in filamentous fungal pathogens.

We observed similar levels of sensitivity in both Aspergillus $m s n A \Delta$ and $A$. fumigatus sak $A \Delta$ mutants to redox-potent phenolic compounds. These similar responses indicated that the signaling route through "SakA-MsnA" might also be governing fungal response to redox-potent phenolics, such as 2,3-DHBA and THY in Aspergillus (Table 2). A recent study showed significant changes occurred in transcription levels of environmental stress response genes of S. cerevisiae treated with THY (Bi et al., 2010). Moreover, these environmental stress genes are mainly controlled by Msn2p/Msn4p transcription factors. These results from S. cerevisiae agree with our findings of the hypersensitivity of the $A$. flavus msnA $\Delta$ mutant. Msn2p/Msn4p-regulated genes contain one or more stress response element (STRE) motifs in their promoter regions (Bi et al., 2010), further emphasizing the important roles of MsnA and/or Msn2p/Msn4p in fungal tolerance to THY.

We also demonstrated the chemosensitization of fungal pathogens to conventional drugs by redox-potent phenolic compounds. We found that THY was a better chemosensitizing agent than 2,3-DHBA in combination with ITZ or AMB. All results with THY, in both filamentous fungi and yeasts, had lowered MFCs of drugs/compounds. Whereas, the least effective chemosensitization was found with 2,3-DHBA plus ITZ. Therefore, there were some unique interrelationships between levels of fungal response and types of chemosensitizers applied. C. neoformans $\mathrm{CN} 24$ was the least sensitive strain to any chemosensitization examined in our test. THY also possessed intrinsic antifungal activity when treated alone (Pinto et al., 2006). However, chemosensitization strategy can lower dosages of THY required for effective control of fungi, as shown in this study.

Fungi could also be sensitized by compounds and antifungal agents that are inhibitor(s) of complex III of the MRC. We were able to demonstrate this with 2,3-DHBA in yeast pathogens. However, there is differential fungal strain sensitivity to chemosensizers/MRC inhibitors (e.g., the low sensitivity of C. krusei CAN75 to 2,3-DHBA plus PCS). Accordingly, doses and/or types of MRC inhibitors or chemosensitizers should be precisely determined for effective control of fungi in the future. Noteworthy is that artemisinin, the wormwood herb used as an antimalarial drug, was recently shown to inhibit the growth of $S$. cerevisiae. In this case, mitochondrial respiration stimulates the effect of this drug, and the mitochondria are subsequently damaged (i.e., depolarization of mitochondrial membrane) by the ROS generated locally (Li et al., 2005).

In conclusion, cellular antioxidant systems can serve as promising molecular targets of redox-potent phenolics for control of fungi. Benzaldehyde analogs, such as 2,3-DHBA, SA, etc., or THY can be developed as chemosensitizing agents to enhance the efficacy of antifungal drugs. Future studies are needed for comprehensive determination of optimum chemosensitization in different fungal pathogens by including additional redox-potent compounds. Further in vivo studies are also warranted to determine if the activities shown in this in vitro study can translate 
into a clinically effective therapeutic strategy for control of fungal pathogens.

\section{ACKNOWLEDGMENTS}

This research was conducted under USDA-ARS CRIS Project 532542000-037-00D. We thank Dr. Gregory S. May at The University

\section{REFERENCES}

An, M., Shen, H., Cao, Y., Zhang, J., Cai, Y., Wang, R., and Jiang, Y. (2009). Allicin enhances the oxidative damage effect of amphotericin B against Candida albicans. Int. J. Antimicrob. Agents 33, 258-263.

Bi, X., Guo, N., Jin, J., Liu, J., Feng, H., Shi, J., Xiang, H., Wu, X., Dong, J., Hu, H., Yan, S., Yu, C., Wang, X., Deng, X., and Yu, L. (2010). The global gene expression profile of the model fungus Saccharomyces cerevisiae induced by thymol. J. Appl. Microbiol. 108, 712-722.

Bink, A., Vandenbosch, D., Coenye, T., Nelis, H., Cammue, B. P., and Thevissen, K. (2011). Superoxide dismutases are involved in Candida albicans biofilm persistence against miconazole. Antimicrob. Agents Chemother. 55, 4033-4037.

Blum, G., Perkhofer, S., Haas, H., Schrettl, M., Würzner, R., Dierich, M. P., and Lass-Flörl, C. (2008). Potential basis for amphotericin B resistance in Aspergillus terreus. Antimicrob. Agents Chemother. 52, 1553-1555.

Chang, P.-K., Scharfenstein, L. L., Luo, M., Mahoney, N., Molyneux, R. J., Yu, J., Brown, R. L., and Campbell, B. C. (2011). Loss of $m s n A$, a putative stress regulatory gene, in Aspergillus parasiticus and Aspergillus flavus increased production of conidia, aflatoxins and kojic acid. Toxins 3, 82-104.

Clemons, K. V., Miller, T. K., Selitrennikoff, C. P., and Stevens, D. A. (2002). fos-1, a putative histidine kinase as a virulence factor systemic aspergillosis. Med. Mycol. 40, 259-262.

Clinical and Laboratory Standards Institute (CLSI). (2008). Reference Method for Broth Dilution Antifungal Susceptibility Testing of Filamentous Fungi: Approved Standard, 2nd Edn. CLSI Document M38-A2. Wayne, PA: Clinical, and Laboratory Standards Institute.

Cuenca-Estrella, M., Moore, C. B., Barchiesi, F., Bille, J., Chryssanthou, E., Denning, D. W., Donnelly, J. P., Dromer, F., Dupont, B., Rex, J. H., Richardson, M. D., Sancak, B., Verweij, P. E., Rodríguez-Tudela, J. L., and AFST Subcommittee of the European Committee on Antimicro- bial Susceptibility Testing. (2003). Multicenter evaluation of the reproducibility of the proposed antifungal susceptibility testing method for fermentative yeasts of the Antifungal Susceptibility Testing Subcommittee of the European Committee on Antimicrobial Susceptibility Testing (AFST-EUCAST). Clin. Microbiol. Infect. 9, 467-474.

de Dios, C. H., Román, E., Monge, R. A., and Pla, J. (2010). The role of MAPK signal transduction pathways in the response to oxidative stress in the fungal pathogen Candida albicans: implications in virulence. Curr. Protein Pept. Sci. 11, 693-703.

Dib, L., Hayek, P., Sadek, H., Beyrouthy, B., and Khalaf, R. A. (2008). The Candida albicans Ddr48 protein is essential for filamentation, stress response, and confers partial antifungal drug resistance. Med. Sci. Monit. 14, BR113-BR121.

González-Párraga, P., SánchezFresneda, R., Zaragoza, O., and Argüelles, J. C. (2011). Amphotericin B induces trehalose synthesis and simultaneously activates an antioxidant enzymatic response in Candida albicans. Biochim. Biophys. Acta 1810, 777-783.

Görner, W., Durchschlag, E., MartinezPastor, M. T., Estruch, F., Ammerer, G., Hamilton, B., Ruis, H., and Schüller, C. (1998). Nuclear localization of the $\mathrm{C}_{2} \mathrm{H}_{2}$ zinc finger protein $\mathrm{Msn} 2 \mathrm{p}$ is regulated by stress and protein kinase A activity. Genes Dev. 12, 586-597.

Graybill, J. R., Burgess, D. S., and Hardin, T. C. (1997). Key issues concerning fungistatic versus fungicidal drugs. Eur. J. Clin. Microbiol. Infect. Dis. 16, 42-50.

Guillen, F., and Evans, C. S. (1994). Anisaldehyde and veratraldehyde acting as redox cycling agents for $\mathrm{H}_{2} \mathrm{O}_{2}$ production by Pleurotus eryngii. Appl. Environ. Microbiol. 60, 2811-2817.

Hamilton, A. J., and Holdom, M. D. (1999). Antioxidant systems in the pathogenic fungi of man and their role in virulence. Med. Mycol. 37, 375-389.

Isenberg, H. D. (1992). Clinical Microbiology Procedures Handbook, 1st Edn. Washington, DC: American Society for Microbiology. of Texas M. D. Anderson Cancer Center, Houston, TX, USA, for providing Aspergillus fumigatus (AF293, sakA $\Delta$ and $m p k C \Delta$ mutants) strains. We also thank Dr. Perng-Kuang Chang at the Southern Regional Research Center, USDA-ARS, New Orleans, LA, USA, for providing A. flavus (CA14 and CA14msnA $\Delta$ mutant) strains.

Jacob, C. (2006). A scent of therapy: pharmacological implications of natural products containing redox-active sulfur atoms. Nat. Prod. Rep. 23, 851-863.

Jaeger, T., and Flohe, L. (2006). The thiol-based redox networks of pathogens: unexploited targets in the search for new drugs. Biofactors 27, 109-120.

Kim, J. H., Campbell, B. C., Mahoney, N., Chan, K. L., and Molyneux, R. J. (2011a). Chemosensitization of aflatoxigenic fungi to antimycin A and strobilurin using salicylaldehyde, a volatile natural compound targeting cellular antioxidation system. Mycopathologia 171, 291-298.

Kim, S. Y., Ko, Y. J., Jung, K. W., Strain, A., Nielsen, K., and Bahn, Y. S. (2011b). Hrk1 plays both Hog1-dependent and -independent roles in controlling stress response and antifungal drug resistance in Cryptococcus neoformans. PLoS ONE 6, e18769. doi:10.1371/journal.pone.0018769

Kim, J. H., Campbell, B. C., Mahoney, N., Chan, K. L., Molyneux, R. J., and Balajee, A. (2010). Augmenting the activity of antifungal agents against aspergilli using structural analogues of benzoic acid as chemosensitizing agents. Fungal Biol. 114, 817-824.

Kim, J. H., Mahoney, N., Chan, K. L., Molyneux, R. J., May, G. S., and Campbell, B. C. (2008a). Chemosensitization of fungal pathogens to antimicrobial agents using benzo analogs. FEMS Microbiol. Lett. 281, 64-72.

Kim, J. H., Campbell, B., Mahoney, N., Chan, K., Molyneux, R., and May, G. (2008b). Chemosensitization prevents tolerance of Aspergillus fumigatus to antimycotic drugs. Biochem. Biophys. Res. Commun. 372, 266-271.

LaFayette, S. L., Collins, C., Zaas, A. K., Schell, W. A., BetancourtQuiroz, M., Gunatilaka, A. A., Perfect, J. R., and Cowen, L. E. (2010). PKC signaling regulates drug resistance of the fungal pathogen Candida albicans via circuitry comprised of $\mathrm{Mkc1}$, calcineurin, and Hsp90. PLoS Pathog. 6, el001069. doi:10.1371/journal.ppat.1001069

Lee, J., Kwon, E. S., Kim, D. W., Cha, J., and Roe, J. H. (2002). Regulation and the role of $\mathrm{Cu}, \mathrm{Zn}$-containing superoxide dismutase in cell cycle progression of Schizosaccharomyces pombe. Biochem. Biophys. Res. Commun. 297, 854-862.

Li, W., Mo, W., Shen, D., Sun, L., Wang, J., Lu, S., Gitschier, J. M., and Zhou, B. (2005). Yeast model uncovers dual roles of mitochondria in action of artemisinin. PLoS Genet. 1, e36. doi:10.1371/journal.pgen.0010036

Miskei, M., Karányi, Z., and Pócsi, I. (2009). Annotation of stressresponse proteins in the aspergilli. Fungal Genet. Biol. 46(Suppl. 1), S105-S120.

Odds, F. (2003). Synergy, antagonism, and what the chequerboard puts between them. J. Antimicrob. Chemother. 52, 1.

Ogita, A., Fujita, K., Taniguchi, M., and Tanaka, T. (2006). Enhancement of the fungicidal activity of amphotericin B by allicin, an allyl-sulfur compound from garlic, against the yeast Saccharomyces cerevisiae as a model system. Planta Med. 72, 1247-1250.

Okamoto, Y., Aoki, S., and Mataga, I. (2004). Enhancement of amphotericin B activity against Can dida albicans by superoxide radical. Mycopathologia 158, 9-15.

O'Rourke, S. M., Herskowitz, I., and O'Shea, E. K. (2002). Yeast go the whole HOG for the hyperosmotic response. Trends Genet. 18, 405-412.

Palacios, D. S., Anderson, T. M., and Burker, M. D. (2007). A postPKS oxidation of the amphotericin B skeleton predicted to be critical for the channel formation is not required for potent antifungal activity. J. Am. Chem. Soc. 129, 13804-13805.

Pinto, E., Pina-Vaz, C., Salgueiro, L., Gonc Cavaleiro, M. J., Palmeira, A., Rodrigues, A., and Martinez-deity of the essential oil of Thymus pulegioides on Candida, Aspergillus and dermatophyte species. J. Med. Microbiol. 55, 1367-1373.

Rao, A., Zhang, Y., Muend, S., and Rao, R. (2010). Mechanism of antifungal activity of terpenoid phenols resembles calcium stress and inhibition of the TOR pathway. 5062-5069. Oliveira, J. (2006). Antifungal activAntimicrob. Agents Chemother. 54, 
Reyes, G., Romans, A., Nguyen, C. K., and May, G. S. (2006). Novel mitogen-activated protein kinase MpkC of Aspergillus fumigatus is required for utilization of polyalcohol sugars. Eukaryot. Cell 5, 1934-1940.

Robbins, N., Uppuluri, P., Nett, J., Rajendran, R., Ramage, G., Lopez-Ribot, J. L., Andes, D., and Cowen, L. E. (2011). Hsp90 governs dispersion and drug resistance of fungal biofilms. PLoS Pathog. 7, e1002257. doi:10.1371/journal.ppat.1002257

Ruis, H., and Schuller, C. (1995). Stress signaling in yeast. Bioessays 17, 959-965.

Smits, G. J., and Brul, S. (2005). Stress tolerance in fungi - to kill a spoilage yeast. Curr. Opin. Biotechnol. 16, 225-230.

Sokol-Anderson, M., Sligh, J. E. Jr., Elberg, S., Brajtburg, J., Kobayashi, G. S., and Medoff, G. (1988). Role of cell defense against oxidative damage in the resistance of Candida albicans to the killing effect of amphotericin B. Antimicrob. Agents Chemother. 32, 702-705.

Sokol-Anderson, M. L., Brajtburg, J., and Medoff, G. (1986). Amphotericin B-induced oxidative damage and killing of Candida albicans. J. Infect. Dis. 154, 76-83.

Takimoto, H., Machida, K., Ueki, M., Tanaka, T., and Taniguchi, M. (1999). UK-2A, B, C and D, novel antifungal antibiotics from Streptomyces sp. 517-02. IV. Comparative studies of UK-2A with antimycin A3 on cytotoxic activity and reactive oxygen species generation in LLCPK1 cells. J. Antibiot. 52, 480-484.

Toone, W. M., and Jones, N. (1998). Stress-activated signalling pathways in yeast. Genes Cells 3, 485-498.

Vandenbosch, D., Braeckmans, K., Nelis, H. J., and Coenye, T. (2010).
Fungicidal activity of miconazole against Candida spp. biofilms. J. Antimicrob. Chemother. 65, 694-700.

Vincent, J. M. (1947). Distortion of fungal hyphae in the presence of certain inhibitors. Nature 159, 850.

Washburn, R. G., Gallin, J. I., and Bennett, J. E. (1987). Oxidative killing of Aspergillus fumigatus proceeds by parallel myeloperoxidase-dependent and -independent pathways. Infect. Immun. 55, 2088-2092.

Xue, T., Nguyen, C. K., Romans, A., and May, G. S. (2004). A mitogenactivated protein kinase that senses nitrogen regulates conidial germination and growth in Aspergillus fumigatus. Eukaryot. Cell 3, 557-560.

Conflict of Interest Statement: The authors declare that the research was conducted in the absence of any commercial or financial relationships that could be construed as a potential conflict of interest.

Received: 23 December 2011; accepted: 22 February 2012; published online: 16 March 2012.

Citation: Kim JH, Chan KL, Faria NCG, Martins MdL and Campbell BC (2012) Targeting the oxidative stress response system of fungi with redox-potent chemosensitizing agents. Front. Microbio. 3:88. doi: 10.3389/fmicb.2012.00088

This article was submitted to Frontiers in Fungi and Their Interactions, a specialty of Frontiers in Microbiology.

Copyright (c) 2012 Kim, Chan, Faria, Martins and Campbell. This is an openaccess article distributed under the terms of the Creative Commons Attribution Non Commercial License, which permits non-commercial use, distribution, and reproduction in other forums, provided the original authors and source are credited. 